\title{
Differential expression pattern of antimicrobial peptides in nasal mucosa and secretion*
}

\author{
Martin Laudien', Stefanie Dressel², Jürgen $\operatorname{Harder}^{2}$, Regine Gläser ${ }^{2}$ \\ Department of Otorhinolaryngology, Head and Neck Surgery, University of Kiel, Kiel, Germany \\ 2 Department of Dermatology, Allergology and Venerology, University Hospital of Schleswig-Holstein, Cam- \\ pus Kiel, Kiel, Germany
}

\begin{abstract}
SUMMARY Objective: The intact nasal barrier is a prerequisite for a functioning defense of the upper airway system, in particular the permanent threat by inhaled potentially harmful microorganisms. Antimicrobial peptides (AMP) play an important role in maintaining barrier function. There is few data about AMP in respect of nasal mucosa. This study is addressed to gain further insight into the differential AMP expression and secretion pattern according to defined anatomical regions of the vestibulum nasi and turbinates.

Patients and Methods: ELISA was applied to quantify concentrations of AMP RNase-7, psoriasin, $h B D-2, h B D-3$ and LL-37 in nasal secretions of 20 healthy volunteers. Immunohistochemistry was used to detect the local cellular sources of AMP in the vestibulum nasi (squamous epithelium) and compared to the mucosa of the turbinates (pseudostratified epithelium) in 10 healthy volunteers.

Results: Expression of RNase 7 and psoriasin was detected in all nasal secretion specimens, whereas $L L-37$ was detected in 16, hBD-2 in 5 and hBD-3 in 6 specimens. In the vestibulum nasi, luminal cell layers were demonstrated as local cellular sources for hBD-3 and RNase 7, whereas psoriasin was found in all layers of the stratified squamous epithelium. LL-37 was detected in 1 stroma cells sample, whereas $h B D-2$ was not detected at all.

In turbinate biopsies, $h B D-3$ and LL-37 were detectable in the epithelium, stroma cells and submucosal glands. RNase 7 was only present in submucosal glands. HBD-2 and psoriasin were not detected.

Conclusion: These data demonstrate that the nasal epithelium contains a chemical defense shield through the expression and secretion of various AMP.
\end{abstract}

Key words: antimicrobial peptide, AMP, nose, nasal secretion

\section{INTRODUCTION}

Acute, recurrent and chronic rhinosinusitis are potentially live threatening diseases and one of the ten highest-prevalence and cost intensive physical health conditions affecting a large number of employers ${ }^{(1-4)}$. The inner lining of the upper airways is the first barrier against possibly invading airborne microorganisms. Several mechanisms are closely connected to preserve the intact barrier of the nose and paranasal sinuses ${ }^{(5)}$. The mechanical barrier consists of vibrissae in the vestibulum nasi, an intact epithelial layer, unimpaired ciliary function, sneezing and cough. Goblet cells and submucosal glands, as well as inflammatory and epithelial cells produce a layer of mucin rich, serous mucus and antimicrobial acting substances, as already described in $1922^{\left({ }^{(}\right)}$. These substances are lysozyme, lactoferrin, secretory $\operatorname{IgA}$ and highly conserved antimicrobial peptides (AMP). AMP act against a broad spectrum of microorganisms like Gram-positive and Gramnegative bacteria, fungi, yeasts and enveloped viruses. They also exhibit chemotactic and immunomodulatory activities (7). Beside expression in phagocytic cells, AMP are mainly expressed in epithelial barrier organs such as skin, gut, respiratory and urogenital tract. The number of identified AMP is steadily increasing and more than 40 human AMP are known so far ${ }^{(8)}$. Major human epithelial AMP-classes are the beta-defensins, cathelicidins, S-100 proteins and ribonucleases (8). We included important members of all these classes in our study: the human beta-defensins (hBD) -2 and -3 , the only human cathelicidin LL-37, the S100 protein psoriasin

List of abbreviations: AMP: antimicrobial peptide(s); BSA: bovine serum albumine; ELISA: enzyme-linked immunosorbent assay; hBD: human beta-defensin; IgA: immunoglobulin A; IL: interleukin; LL-37: human cathelicidin; psoriasin: S100 A7c; RNase-7: ribonuclease 7; RT-PCR: real-time polymerase chain reaction; $S$. aureus: Staphylococcus aureus; TBS: TRIS buffered saline; TNF: tumor necrosis factor 


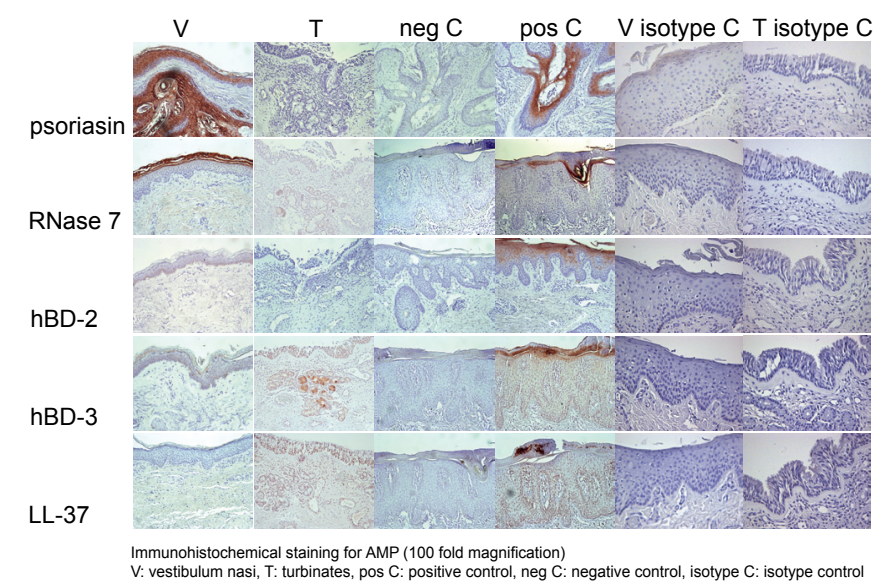

Figure 1. Immunohistochemical staining for AMP (100 fold magnification). V: vestibulum nasi, $\mathrm{T}$ : turbinates, pos $\mathrm{C}$ : positive control, neg $\mathrm{C}$ : negative control, isotype $\mathrm{C}$ : isotype control

(S100 A7c) and the ribonuclease RNase 7. The expression of these epithelial-derived AMP is induced at sites of infection and inflammation. In the skin, AMP induction is triggered by proinflammatory cytokines such as Interleukin (IL)-1, IL-17, IL-22, tumor necrosis factor (TNF)- $\alpha$, wound healing, epidermal differentiation and bacterial contact ${ }^{(9,10)}$.

Little attention was paid until now to the upper respiratory tract, especially to the vestibulum nasi and nasal cavity, even though this is the place of first contact of inhaled microorganisms to the body. So far, nothing is known about RNase 7 and psoriasin in nasal secretion or about their endonasal origin. A protein like hBD-3 has not been investigated in nasal secretion yet, but could be detected by RT-PCR in nasal biopsies ${ }^{(11)}$. HBD-2 was shown to be detectable in nasal fluid by ELISA and western blot analysis. It was induced in patients with Staphylococcus (S.) aureus colonization compared to healthy controls and acute rhinitis patients ${ }^{(12,13)}$. Induction of hBD-2 in airway cell culture by Pseudomonas aeruginosa and IL-1 $\beta$ was described ${ }^{(14,15)}$.

Presence of LL-37 was already demonstrated by western blot and ELISA in nasopharyngeal surface fluid and nasal secretion with widely interindividual varying concentrations. LL-37 was also shown to be inducible by lipopolysaccharide and lipoteichoic acid stimulation ${ }^{(16-18)}$.

There are no systematic investigations comparing the vestibulum nasi (squamous epithelium) to the mucosa (cilia bearing pseudostratified epithelium) of the inner nose about cellular sources of different classes of antimicrobial peptides.

In the present study, we used immunohistochemistry to systematically analyse expression of various classes of AMP in biopsies of the vestibulum nasi in comparison with those of turbinates. Moreover, secretion of different classes of AMP in nasal fluids was investigated by ELISA. The results are demanding for the understanding of the innate immune system of nasal epithelium and a prerequisite for further investigations of inflammatory diseases of the upper respiratory tract. Keeping in mind the increasing development of antibiotic (multi-) resistance in microorganisms and the challenging therapy of recurrent self-infections, especially with $S$. aureus but also other microorganisms carried in the nose, AMP will become even more interesting as therapeutic agents as they already are in use ${ }^{(19)}$.

\section{PATIENTS AND METHODS}

\section{Immunohistochemistry}

Biopsies of ten healthy volunteers ( $\mathrm{f}=5, \mathrm{~m}=5$ ) with a mean age of 36 y (14 - 67 y) were included in this study. The nasal mucosa was investigated by endoscopy and persons with signs of inflammation or systemic infection (fever, leucocytosis) were excluded as well as individuals with atopic diseases, antibiotic or immunosuppressive treatment and pregnancy. Biopsies were taken while performing airway passage improving surgery. The study was approved by the ethics committee of the University of Kiel (AZ A101/07), and participants gave written informed consent. Biopsies showed no signs of accentuation of inflammatory cell influx and were obtained from the vibrissae bearing skin of the vestibulum nasi and from the cilia bearing mucosa of the turbinates. Skin biopsies of psoriasis patients served as controls.

Sections of $5 \mu \mathrm{m}$ thickness were deparaffinized and rehydrated before heat-induced antigen retrieval was performed in 0.01 $\mathrm{M}$ citrate buffer ( $\mathrm{pH}$ 6.0). The slides were blocked with normal rabbit serum (1:75, Dako Cytomation, Glostrup, Denmark) for psoriasin. Slides for hBD-2, RNase 7, hBD-3 and LL-37 were blocked with TBS-buffer containing 12\% BSA (Sigma-Aldrich, Deisenhofen, Germany). Staining was performed at room temperature for $1 \mathrm{hr}$ using a murine monoclonal anti-Psoriasin antibody (HL15-4, 1:8000; kindly provided by H. Lange, Kiel, Germany), polyclonal goat anti-RNase $7\left(1: 400,{ }^{(20)}\right)$, goat antihBD-2 (1:500, Pepro Tech Cell, NJ, USA), rabbit anti-hBD-3 antibodies (1:500, Peprotech Cell Concepts) and polyclonal rabbit anti-LL-37 antibodies (1:150, Innovagen, Lund, Sweden). The following biotinylated secondary antibodies were used: rabbit anti-mouse $\operatorname{IgG}$ (1:200, Dako Cytomation), rabbit anti-goat IgG (1:500, Jackson ImmunoResearch, West Grove, PA, USA) pig anti-rabbit IgG (1:300, Dako Cytomation) and followed by incubation with Vector Universal ABC Peroxidase Substrate Kit (Vector, Burlingame, CA, USA) developed with Vector NovaRED Substrate (SK-4800) and counterstained with hematoxylin. Isotype controls were stained to ensure specificity of immunohistochemistry (negative control rabbit immunoglobulin fraction (Dako) LL-37, hBD-3), negative control Mouse IgG2a (Dako) (Psoriasin), isotype control goat IgG (Gen Way Biotech Inc, San Diego, CA, USA) (RNase7, hBD-2).

\section{ELISA}

To analyse the AMP concentration in nasal secretions, swabs of 20 volunteers ( $f=14, \mathrm{~m}=6$, mean age: $32.5 \mathrm{y}$, range: 26 - 54 y) were taken. Participants were free of acute inflammatory processes of the inner nose, atopic diseases and antibiotic or immunosuppressive treatment. All participants gave written 
informed consent and the study protocol was approved by the ethic committee of the University of Kiel (AZ A 104/06).

Swabs were taken by inserting the tip into both nostrils at the six o'clock position for three seconds and subsequently wiping the mucosa in circular movements three times. Afterwards the swab was eluted in $1 \mathrm{ml} 10 \mathrm{mM}$ sodium-phosphate buffer containing $150 \mathrm{mM} \mathrm{NaCl}(\mathrm{pH} 7.1)$ and $1 \%$ bovine serum albumin (Sigma, Deisenhofen, Germany) for 10-15 minutes. Thereafter, the swab was centrifuged at $1000 \mathrm{rpm}$ for 1 minute to recover the remaining eluate. All samples were stored at $-80^{\circ} \mathrm{C}$ until further processing.

Psoriasin and LL-37 were analysed by ELISA according to standard protocols ${ }^{(21,22)}$. For detection of RNase 7, an ELISA with affinity-purified polyclonal goat antibodies against RNase 7 was used as recently described ${ }^{(20)}$. HBD-2 and -3 were quantified using commercially available ELISA kits (Peprotech, Hamburg, Germany and Acris, Herford, Germany). Detection limits of the ELISA were $0.6 \mathrm{ng} / \mathrm{ml}$ for psoriasin, $0.3 \mathrm{ng} / \mathrm{ml}$ for LL-37, $2.5 \mathrm{ng} / \mathrm{ml}$ for RNase 7, $0.3 \mathrm{ng} /$ $\mathrm{ml}$ for $\mathrm{hBD}-2$ and $1.6 \mathrm{ng} / \mathrm{ml}$ for hBD-3.

\section{RESULTS}

Immunohistochemistry

\section{Vestibulum nasi}

Psoriasin was found in all layers of the stratified squamous epithelium and RNase 7 in the luminal cell layers of the stratum corneum and granulosum. HBD-3 showed the same expression pattern as RNase 7, whereas hBD-2 could not be detected at all. LL-37 was detected in only one sample with slight staining in only few stroma cells (Table 1 and Figure $1 \mathrm{~A})$.

\section{Mucosa turbinate}

Psoriasin could not be detected in biopsies of the cilia bearing mucosa, whereas RNase 7 expression was restricted to the submucosal glands and was only detectable in 2 samples. HBD-3 was detectable in 3 samples. For hBD-3 and LL-37 positive immunostaining was seen in the epithelium, stroma cells and submucosal glands, whereas hBD-2 was not detectable (Table 1 and Figure 1B). Real time PCR data show expression of all AMP in turbinate specimens of healthy volunteers (data not shown).

\section{ELISA}

Secretion of psoriasin and RNase 7 was detected in all 20 samples (mean concentration $19.13 \mathrm{ng} / \mathrm{ml}$ and $18.26 \mathrm{ng} /$ $\mathrm{ml}$, respectively). LL-37 could be detected in 16 probes (mean concentration $4.34 \mathrm{ng} / \mathrm{ml}$ ), hBD-2 in 5 probes (mean concentration $0.82 \mathrm{ng} / \mathrm{ml}$ ) and $\mathrm{hBD}-3$ in 6 probes (mean concentration $2.79 \mathrm{ng} / \mathrm{ml}$ ) (Figure 2). All other samples were below the detection limit of the ELISA.

\section{DISCUSSION}

A balanced commensal bacterial flora of the nose is the prerequisite for an intact mucosal barrier and prevents inflammation ${ }^{23)}$. However, in immunocompromised patients such as patients on haemodialysis, recurrent infections with S. aureus are mainly caused by nasal carriage and could be prevented by eradication ${ }^{\left({ }^{19}\right)}$. In this system, AMP may play an important role in growth control, as it is already known for the skin ${ }^{(24)}$.

\section{Concentration of AMP in nasal secretion}

AMP are gene encoded highly effective antibiotics ${ }^{(25)}$. Some AMP show effective killing in vitro in concentrations as low as $1-10 \mu \mathrm{g} / \mathrm{ml}$, but sensitivity against AMP of metabolic inactive bacteria and different strains is highly variable ${ }^{(26,27)}$.

In this study, the detected concentrations in nasal secretion were similar or even higher as levels detected in washing fluids of healthy skin ${ }^{(28)}$. Taking into consideration that swabs are eluted in 1,000 $\mu$ land collected nasal secretion is highly diluted that way (up to 1,000 fold), the detected concentrations may reach physiological relevant killing concentrations. The in vivo AMP amounts on epithelial and mucosal surfaces, which are responsible for effective bacterial killing, are not directly measurable. One factor influencing the measured AMP value is their concentration gradient towards the nasal cavity, which might lead to underestimation of AMP concentrations at sites

\begin{tabular}{|c|c|c|c|c|c|c|}
\hline & \multicolumn{3}{|c|}{ vestibulum nasi } & \multicolumn{3}{|c|}{ turbinate } \\
\hline & epithelium & stroma cells & $\begin{array}{c}\text { submucosal } \\
\text { glands }\end{array}$ & epithelium & stroma cells & $\begin{array}{c}\text { submucosal } \\
\text { glands }\end{array}$ \\
\hline hBD-2 & No & no & no & no & no & no \\
\hline hBD-3 & $\begin{array}{l}\text { luminal (SC, slightly } \\
\text { SG) }\end{array}$ & no & no & yes & yes & yes \\
\hline LL-37 & No & no & no & yes & yes & Yes \\
\hline $\begin{array}{l}\text { psoriasin } \\
(\mathrm{S} 100 \mathrm{~A} 7 \mathrm{c})\end{array}$ & all epithelial layers & no & no & no & no & No \\
\hline RNase 7 & $\begin{array}{l}\text { luminal (SC, slightly } \\
\text { SG) }\end{array}$ & no & no & no & no & Yes \\
\hline
\end{tabular}

Table 1. AMP distribution in the nasal mucosa detected by immunohistochemistry of representative biopsies derived from healthy individuals $(\mathrm{n}=10$ ). SC:stratum corneum, SG:stratum granulosum 


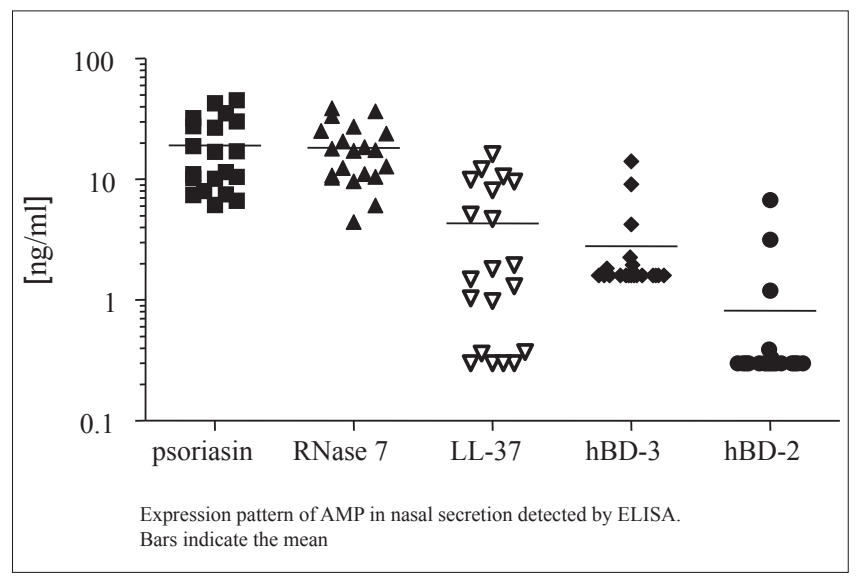

Figure 2. Expression pattern of AMP in nasal secretion detected by ELISA. Bars indicate the mean.

of bacterial encountering like mucosa and intercellular space (18). In addition, the known synergistic and additive AMP effects ${ }^{(29-31)}$ may play an important role in the nasal mucosa. On the other hand, potential AMP-inhibiting components of nasal secretion like salt concentrations are not investigated so $\operatorname{far}^{(32)}$.

\section{Cellular sources}

Cellular sources of AMP in nasal secretion might be mucosa cells (epithelium, glands, connective tissue) and infiltrating cells like granulocytes ${ }^{(18)}$. In this study, sources of several classes of AMP (psoriasin, RNase 7, hBD-2, -3 and LL 37) in the vestibulum nasi (squamous epithelium) and turbinates (pseudostratified epithelium) in healthy participants were investigated.

In contrast to the squamous epithelium of the vestibulum nasi, where psoriasin and RNase 7 had been detected in the epithelium, only RNase 7 expression could be verified in the submucosal glands of the turbinates, even though both of these AMP are constitutively expressed on skin. This is one obvious difference between squamous and pseudostratified epithelium of the inner nose.

The epithelial expression of hBD-3 in the vestibulum nasi is comparable to the differentiated epithelial skin layers where keratinocytes are described as cellular source of beta-defensins (9). HBD-2 could not be detected by immunohistochemistry neither in the vestibulum nasi nor in the turbinates. In concordance with these data, hBD-2 was only detectable in a few nasal secretions of healthy participants at lowest concentrations of all AMP under investigation. Since hBD-2 is an inducible AMP known to be strongly upregulated during inflammation ${ }^{(13-15,33-36)}$, it is likely that its expression in the nasal mucosa is induced during inflammation and infection. In line with this hypothesis, Lee et al. have shown an increased hBD-2 gene expression in the nasal mucosa of patients with chronic sinusitis ${ }^{(35)}$. The recent observation that a nasal carrier strain of $S$. aureus - in contrast to a non-carrier strain - suppressed the induction of hBD-2 and hBD-3 in nasal epithelial cells underlines a potential important role of beta-defensins in the interaction between nasal mucosa and microbes ${ }^{(33)}$.

We detected immunoreactivity of LL-37 in stroma cells of the turbinates. The described distribution of LL-37 and hBD-3 in turbinates is in line with the literature, where expression of these AMP has been detected in epithelial cells, inflammatory cells in subepithelial layers and submucosal glands ${ }^{(11,17,34,36-40)}$.

\section{CONCLUSION}

Taken together, the high amounts of AMP detected in the nasal fluids suggest that AMP may play an important role in the mucosal defense of the nose, a hypothesis that has to be addressed in further studies. Dysregulation of defensins has been described for various infectious and inflammatory diseases such as enteric Shigella and Mycobacterium tuberculosis infections, cystic fibrosis and Crohn's disease ${ }^{(9)}$. Results of this study could be the basis for investigations of a hypothetical dysregulation in infectious and autoimmune diseases of the nose and paranasal sinuses like chronic rhinosinusitis, acute and fungal rhinosinusitis, Wegener's Granulomatosis, ChurgStrauss syndrome, Mycobacterium tuberculosis, pox infections, and cystic fibrosis. A better understanding of AMP regulation in the nose might result in improvement of therapy.

\section{ACKNOWLEDGEMENTS}

We thank Christel Martensen-Kerl, Vera Beck-Jendroschek, Yuan Hui, Maike Luisa Thienhaus, Anne-Marie Röen and Janet Wohlers for excellent technical assistance.

This study was supported by grants of the Federal Ministry of Education and Research (BMBF, SkinStaph) given to R. Gläser and J. Harder and by the German Research Foundation (DFG) funded Clinical Research Unit / KFO 170. J. Harder was supported by a Heisenberg-program of the DFG.

\section{REFERENCES}

1. Goetzel RZ, Long SR, Ozminkowski RJ, et al. Health, absence, disability, and presenteeism cost estimates of certain physical and mental health conditions affecting U.S. employers. J Occup Environ Med. 2004; 46: 398-412.

2. Bachert C, Van Bruaene N, Toskala E, et al. Important research questions in allergy and related diseases: 3-chronic rhinosinusitis and nasal polyposis - a GALEN study. Allergy. 2009; 64: 520-533.

3. Fokkens W, Lund V, Mullol J. European position paper on rhinosinusitis and nasal polyps 2007. Rhinol Suppl. 2007; 1-136.

4. Thomas M, Yawn BP, Price D, et al. EPOS Primary Care Guidelines: European Position Paper on the Primary Care Diagnosis and Management of Rhinosinusitis and Nasal Polyps 2. Prim Care Respir J. 2008; 17: 79-89.

5. Bals R. Epithelial antimicrobial peptides in host defense against infection. Respir Res. 2000; 1: 141-150.

6. Fleming A. On a remarkable bacteriolytic element found in tissues and secretions. Proc R Soc Lond B Biol Sci. 1922; 93: 306-317.

7. De Smet K, Contreras R. Human antimicrobial peptides: defensins, cathelicidins and histatins. Biotechnol Lett. 2005; 27 : 1337-1347.

8. Harder J, Glaser R, Schroder JM. Human antimicrobial proteins effectors of innate immunity. J Endotoxin Res. 2007; 13: 317-338.

9. Harder J, Glaser R, Schroder JM. The role and potential therapeutical applications of antimicrobial proteins in infectious and inflammatory diseases. Endocr Metab Immune Disord Drug Targets. 2007; 7: 75-82.

10. Sorensen OE, Cowland JB, Theilgaard-Monch K, et al. Wound 
healing and expression of antimicrobial peptides/polypeptides in human keratinocytes, a consequence of common growth factors. J Immunol. 2003; 170: 5583-5589.

11. Harder J, Bartels J, Christophers E, et al. Isolation and characterization of human beta -defensin-3, a novel human inducible peptide antibiotic. J Biol Chem. 2001; 276: 5707-5713.

12. Cole AM, Dewan P, Ganz T. Innate antimicrobial activity of nasal secretions. Infect Immun. 1999; 67: 3267-3275.

13. Cole AM, Tahk S, Oren A, et al. Determinants of Staphylococcus aureus nasal carriage. Clin Diagn Lab Immunol. 2001; 8: 10641069.

14. Meyer JE, Harder J, Gorogh T, et al. [hBD-2 gene expression in nasal mucosa]. Laryngorhinootologie. 2000; 79: 400-403.

15. Singh PK, Jia HP, Wiles K, et al. Production of beta-defensins by human airway epithelia. Proc Natl Acad Sci U S A. 1998; 95 : 14961-14966.

16. Lysenko ES, Gould J, Bals R, et al. Bacterial phosphorylcholine decreases susceptibility to the antimicrobial peptide LL-37/ hCAP18 expressed in the upper respiratory tract. Infect Immun. 2000; 68: 1664-1671.

17. Nell MJ, Tjabringa GS, Vonk MJ, et al. Bacterial products increase expression of the human cathelicidin hCAP-18/LL-37 in cultured human sinus epithelial cells. FEMS Immunol Med Microbiol. 2004; 42: 225-31.

18. Tjabringa GS, Vos JB, Olthuis D, et al. Host defense effector molecules in mucosal secretions. FEMS Immunol Med Microbiol. 2005; 45: 151-158

19. Wertheim HF, Melles DC, Vos MC, et al. The role of nasal carriage in Staphylococcus aureus infections. Lancet Infect Dis. 2005; 5: 751-762.

20. Koten B, Simanski M, Glaser R, et al. RNase 7 contributes to the cutaneous defense against Enterococcus faecium. PLoS One 2009; 4: e6424.

21. Glaser R, Harder J, Lange H, et al. Antimicrobial psoriasin (S100A7) protects human skin from Escherichia coli infection. Nat Immunol. 2005; 6: 57-64

22. Brandenburg LO, Varoga D, Nicolaeva N, et al. Role of glial cells in the functional expression of LL-37/rat cathelin-related antimicrobial peptide in meningitis. J Neuropathol Exp Neurol. 2008; 67: 1041-1054

23. Nell MJ, Tjabringa GS, Vonk MJ, et al. Bacterial products increase expression of the human cathelicidin hCAP-18/LL-37 in cultured human sinus epithelial cells. FEMS Immunol Med Microbiol. 2004; 42: 225-231.

24. Harder J, Schroder JM. Antimicrobial peptides in human skin. Chem Immunol Allergy. 2005; 86: 22-41.

25. Zasloff M. Antimicrobial peptides of multicellular organisms. Nature. 2002; 415: 389-395.

26. Ganz T. Defensins: antimicrobial peptides of innate immunity. Nat Rev Immunol. 2003; 3: 710-720.

27. Sahly H, Schubert S, Harder J, et al. Burkholderia is highly resistant to human Beta-defensin 3. Antimicrob Agents Chemother. 2003; 47: 1739-1741.

28. Glaser R, Meyer-Hoffert U, Harder J, et al. The antimicrobial protein psoriasin (S100A7) is upregulated in atopic dermatitis and after experimental skin barrier disruption. J Invest Dermatol.
2009; 129: 641-649.

29. Chen X, Niyonsaba F, Ushio H, et al. Synergistic effect of antibacterial agents human beta-defensins, cathelicidin LL-37 and lysozyme against Staphylococcus aureus and Escherichia coli. J Dermatol Sci. 2005; 40: 123-312.

30. Ganz T. Antimicrobial polypeptides. J Leukoc Biol. 2004; 75: 34-38.

31. Laube DM, Yim S, Ryan LK, et al. Antimicrobial peptides in the airway. Curr Top Microbiol Immunol. 2006; 306: 153-182.

32. Travis SM, Conway BA, Zabner J, et al. Activity of abundant antimicrobials of the human airway. Am J Respir Cell Mol Biol. 1999; 20: 872-879.

33. Quinn GA, Cole AM. Suppression of innate immunity by a nasal carriage strain of Staphylococcus aureus increases its colonization on nasal epithelium. Immunology 2007; 122: 80-89.

34. Ooi EH, Wormald PJ, Tan LW. Innate immunity in the paranasal sinuses: a review of nasal host defenses. Am J Rhinol. 2008; 22: 13-19.

35. Lee SH, Kim JE, Lim HH, et al. Antimicrobial defensin peptides of the human nasal mucosa. Ann Otol Rhinol Laryngol. 2002; 111: $135-141$.

36. Chen PH, Fang SY. The expression of human antimicrobial peptide LL-37 in the human nasal mucosa. Am J Rhinol. 2004; 18: 381-385.

37. Duits LA, Rademaker M, Ravensbergen B, et al. Inhibition of hBD-3, but not hBD-1 and hBD-2, mRNA expression by corticosteroids. Biochem Biophys Res Commun. 2001; 280: 522-525.

38. Kim ST, Cha HE, Kim DY, et al. Antimicrobial peptide LL-37 is upregulated in chronic nasal inflammatory disease. Acta Otolaryngol. 2003; 123: 81-85.

39. Ooi EH, Wormald PJ, Carney AS, et al. Fungal allergens induce cathelicidin LL-37 expression in chronic rhinosinusitis patients in a nasal explant model. Am J Rhinol. 2007; 21: 367-372.

40. Ooi EH, Wormald PJ, Carney AS, et al. Human cathelicidin antimicrobial peptide is up-regulated in the eosinophilic mucus subgroup of chronic rhinosinusitis patients. Am J Rhinol. 2007; 21: $395-401$

\author{
Martin Laudien \\ Department of Otorhinolaryngology \\ Head and Neck Surgery \\ University of Kiel \\ Arnold-Heller-Straße 14 \\ D-24105 Kiel \\ Germany \\ Tel.: +49 431597 2324/2241 \\ Fax.: +49 4315972272 \\ E-mail: 1audien@hno.uni-kiel.de
}

